\title{
PEMBENTUKAN WILAYAH PERTAHANAN PRIAGAN TIMUR DAN PERPINDAHAN IBUKOTA PROPINSI JAWA BARAT KE LEBAKSIUH TAHUN 1947-1948
}

\author{
Alex Anis Ahmad \\ Jurusan Pendidikan Sejarah, Universitas Siliwangi, Indonesia \\ Email: alexanisahmad@unsil.ac.id
}

\begin{abstract}
This article describes the process of forming Wehrkreise III as the East Priangan defense area and the transfer of the administrative center of West Java Province to Lebaksiuh in 1947-1948. The research method used is the historical method. The results of this study indicate that the onslaught of the Dutch military in West Java during the years 1947-1948 was faced by the struggle agencies by forming defense pockets called Wehrkreise III. Each defense bag can do its own guerrilla battle. The Commander of Wehrkreise not only oversees the struggle agencies but also oversees the civil administration in West Java. The Wehrkreise command center and the West Java provincial government center were initially in Tasikmalaya. But the Dutch military offensive made the Governor of West Java and the Wehrkreise commander move their seat to Lebaksiuh. This move was intended so that the republican government in West Java could continue to run because Lebaksiuh was a relatively safe area from Dutch attacks.
\end{abstract}

Keywords: East Priangan, Indonesian Revolution, Lebaksiuh, Wehrkreise

\begin{abstract}
Abstrak
Atikel ini menjelaskan tentang proses pembentukan Wehrkreise III sebagai wilayah pertahanan Priangan Timur dan pemindahan pusat pemerintahan Propinsi Jawa Barat ke Lebaksiuh pada tahun 1947-1948. Metode penelitian yang digunakan adalah metode sejarah. Hasil kajian ini menunjukkan bahwa serangan militer Belanda yang begitu gencar di Jawa Barat sepanjang tahun 1947-1948 dihadapi oleh badan-badan perjuangan dengan membentuk kantong-kantong pertahanan yang diberinama Wehrkreise III. Setiap kantong pertahanan dapat melakukan pertempuran gerilya sendiri. Komandan Wehrkreise tidak hanya membawahi badan-badan perjuangan, tetapi juga membawahi pemerintahan sipil di Jawa Barat. Pusat komando Wehrkreise dan pusat pemerintahan Propinsi Jawa Barat awalnya berada di Tasilmalaya. Namun serangan militer Belanda membuat Gubernur Jawa Barat dan komandan Wehrkreise memindahkan tempat kedudukan mereka ke Lebaksiuh. Perpindahan ini bertujuan agar pemerintahan republik di Jawa Barat dapat tetap berjalan karena Lebaksiuh merupakan daerah yang relatif aman dari serangan Belanda.
\end{abstract}

Kata Kunci: Priangan Timur, Revolusi Indonesia, Lebaksiuh, Wehrkreise 


\section{PENDAHULUAN}

Pada tahun 1947, ketika Belanda melancarkan agresi militer, badan-badan perjuangan di Jawa Barat membentuk wilayah pertahanan yang disebut dengan Wehrkreise III. Wilayah pertahanan ini berada di bawah komando Letnan Kolonel Sutoko. Sebagai komandan Wehrkreise III, Sutopo membawahi pemerintahan sipil di Jawa Barat. Saat itu, pemerintahan sipil di Jawa Barat dipimpin oleh Gubernur Sewaka.

Ketika Jawa Barat terus diserang oleh militer Belanda, Sewaka dan Sutopo berkali-kali memindahkan tempat kedudukannya, mulai dari Padayungan, Tasilmalaya hingga Lebaksiuh. Tujuannya untuk menghindari serangan militer Belanda, serta menunjukkan kepada Belanda bahwa aktivitas pemerintahan di Jawa Barat masih tetap berjalan.

Pada tahun 1947, Lebaksiuh masih kampung yang terletak kurang lebih $70 \mathrm{~km}$ di selatan Kota Tasikmalaya. Lebaksiuh berada di Desa Cipicung, Kecamatan Bantarkalong, Kewedanan Karangnunggal. Lebaksiuh dikelilingi oleh hutan belantara yang dihuni oleh beberapa binatang buas, di antaranya macan tutul, banteng dan beberapa jenis kera. Saat itu, Lebaksiuh dikenal sebagai "Kepunduhan Lebaksiuh" yang dipimpin oleh seorang "punduh" yang bernama Abdul Samad. Di kepunduhan inilah Sewaka, Gubernur Jawa Barat, membuka kantor darurat untuk menjalankan pemerintahannya. Pemerintahan Sewaka di Lebaksiuh berlangsung sejak Agustus 1947 sampai Februari 1948. Keputusan Sewaka berkantor di Lebaksiuh merupakan beleid (kebijaksanaan) sendiri karena saat itu hubungan dengan Yogyakarta, ibu kota negara, sedang terputus.

Perjalanan Gubernur Sewaka dari pusat kecamatan Karangnunggal menuju Lebaksiuh mengambil rute dari Pamijahan menuju Panyalahan, kemudian diteruskan ke Kampung Cilumbu hingga tiba di Kampung Lebaksiuh. Perpindahan ini bukanlah sesuatu yang di luar rencana. Pada saat itu kepala Desa Cipicung, Raden Djarkasih, telah menerima berita dari seorang kurir bahwa rombongan Gubernur Sewaka akan menetap di Lebaksiuh. Mendengar berita itu, Raden Djakarsih segera memerintahkan beberapa pemuda desa untuk menjemput rombongan gubernur sekaligus sebagai penunjuk jalan. Rombongan terdiri dari gubernur bersama istri dan puterinya Juag Nani, sekertaris gubernur (Enoch) dan istrinya (Nyonya Loho), ajudan gubernur (Kapten Sulaeman) dan supir gubernur beserta istri dan anak-anaknya, residen Bogor (Barnas) dan putrinya Juag Ita, serta residen Priangan (Ardiwinangun). Selain itu, rombongan gubernur juga didampingi oleh beberapa orang reporter dari Kantor Berita Antara. Mereka adalah A.Z. Palindih, Moch. Royani dan Moch. Saman. Mereka menempuh perjalanan dengan medan yang berat, mulai dari menerobos hutan belantara sampai mendaki gunung dan bukit yang terjal.

Selama mengungsi di Lebaksiuh, keluarga gubernur dan seluruh stafnya ditampung di rumah penduduk setempat. Dalam hal ini, rumah H. Abdul Hamid, seorang khotib di Lebaksiuh yang cukup terpandang dan memiliki persawahan yang cukup luas, ditempati oleh gubernur dan keluarganya. Bahkan rumah Abdul Hamid juga digunakan sebagai kantor oleh Gubernur Sewaka. Para reporter dari Kantor Berita Antara menempati rumah Abdul Fatah. Residen Bogor dan putrinya Jung Ita menempati rumah Ibu Rumsih. Sementara itu, pengungsi lainnya disebar di rumah-rumah penduduk.

Dipilihnya Lebaksiuh menjadi pusat pemerintahan Provinsi Jawa Barat merupakan upaya gubernur untuk mengamankan dan menyelamatkan kedudukan Provinsi Jawa Barat, serta sebagai bagian dari usaha mempertahankan dan menegaskan kedaulatan Republik Indonesia dari ancaman agresi kedua militer Belanda. Usaha-usaha yang dilakukan gubernur untuk meyakinkan masih eksisnya pemerintahan Propinsi Jawa Barat dilakukan dengan terlebih dahulu memberikan instruksi kepada para residen dan bupati agar mereka tetap menjalankan kewajibannya sebagai pegawai Republik 
Indonesia dan supaya berusaha menghindari penangkapan Belanda. Jika kemungkinan untuk menyingkir tidak ada, maka mereka harus menyatakan diri non-aktif.

Berdasarkan latar belakang di atas, tulisan ini berfokus pada proses pembentukan Wehrkreise III sebagai wilayah pertahanan Priangan Timur dan pemindahan pusat pemerintahan Propinsi Jawa Barat ke Lebaksiuh pada tahun 1947-1948. Kajian ini diharapkan dapat memperkaya historiografi revolusi Indonesia.

\section{METODE PENELITIAN}

Kajian ini dilakukan dengan menggunakan metode sejarah. Menurut Abdurahman (1999: 133), metode sejarah adalah proses yang dilaksanakan oleh sejarawan dalam usaha mencari, mengumpulkan dan menyajikan fakta sejarah serta tafsirannya dalam susunan yang teratur. Pendapat lain menyatakan bahwa metode sejarah merupakan suatu proses menguji dan menganalisis secara kritis rekaman dan peninggalan masa lampau (Gottschlak, 2008: 39).

Metode sejarah memiliki empat tahapan. Pertama, pengumpulan sumber atau heuristik. Sumber yang digunakan dalam kajian ini berupa buku dan artikel ilmiah yang diperoleh dari beberapa perpustakaan di Jawa Barat. Tahap kedua adalah melakukan verifikasi sumber untuk memperoleh fakta-fakta sejarah yang kredibel. Ketiga, melakukan interpretasi berdasarkan kronologi dan sebab akibat. Keempat, historiografi atau penulisan (Garraghan, 1957).

\section{HASIL DAN PEMBAHASAN Pembentukan Wehrkreise III}

Setelah proklamasi kemerdekaan Indonesia tahun 1945, para pemuda dan tokoh-tokoh pergerakan di Jawa Barat membentuk badanbadan perjuangan, seperti LASWI, Hizbullah, Sabilillah, Barisan Merah Putih (BMP), Barisan Banteng Republik Indonesia (BBRI), Barisan Berani Mati (BBM), Angkatan Pemuda Indonesia (API), Laskar Rakyat (LR), Pasukan Istimewa (PI), Pasukan Garuda Putih (PGP),
Pasukan Beruang Merah (PBM), Angkatan Muda Kereta Api (AMKA), Angkatan Muda PTT, Pemuda Sosial Indonesia (PESINDO). Badan-badan perjuangan itu tergabung dalam Majelis Persatuan Pertahanan Priangan (MPPP) yang dipimpin oleh Letnan Kolonel Sutoko (Disjarah, 1965).

Ketika Sutoko berpindah ke Tasikmalaya pada tanggal 1 Juli 1947, ia diangkat menjadi Kepala Staf Pertahanan Jawa Barat atau komandan Wehrkreise III di bawah pimpinan A.H. Nasution. Di bidang teritorial, Sutopo membawahi pemerintahan sipil Jawa Barat yang saat itu gubernurnya dijabat oleh Sewaka. Berkenaan hal itu, pemerintahan sipil Jawa Barat menjadi bagian dalam Wehrkreise III dan menetap di Tasikmalaya. Dengan demikian, pemerintah Provinsi Jawa Barat untuk sementara menjalankan aktivitasnya di Kota Tasikmalaya. Untuk mengetahui segala aktivitas gerakan gerilya dari pasukan Siliwangi, Sutoko selalu mendampingi gubernur, sehingga ia dengan mudah dapat memberikan informasi kepada gubernur bahwa pasukan Siliwangi masih eksis dan selalu berusaha mengatasi kemungkinankemungkinan patroli tentara Belanda yang berusaha menyerang, melumpuhkan dan menawan seluruh aparat pemerintahan, baik sipil maupun militer (Disjarah, 1994).

Wehrkreise memiliki pengertian sebagai daerah pertempuran dalam lingkaran-lingkaran (kreise) yang dapat mengadakan pertempuran (wehr) secara berdiri sendiri. Lingkaranlingkaran pada hakekatnya adalah kantongkantong perlawanan gerilya sesuai dengan konsep perang wilayah yang dikembangkan pasukan Siliwangi. Setiap pasukan yang berhasil menyusun diri kembali mulai melakukan gerilya dengan dibantu sepenuhnya oleh rakyat.

Susunan komando Wehrkreise III di antaranya: (1) Letnan Kolonel Sutoko sebagai komandan Wehrkreise III; (2) Letnan Sugianto selaku Kepala Pengawal Komandan; (3) dr. Akil Asikin sebagai dokter tentara; dan (4) anggotaanggota pengawal yang terdiri dari Sersan 
Wahyu, Sersan Komar, Sersan Rahmat, Sersan Wisoko, Kopral Udis, Pratu Empud dan Serma Sopyan (sopir komandan) (Disjarah, 1994).

Wilayah Wehrkreise III meliputi Tasikmalaya, Ciamis selatan sampai dengan perbatasan Jawa Tengah. Sewaktu Belanda melancarkan agresi militer pertama, kedudukan pos komando Wehrkreise III selalu berpindah-pindah, mulai dari Padayungan yang terletak kurang lebih 3 $\mathrm{km}$ dari pusat kota Tasikmalaya, Cibalong yang berada kurang lebih $26 \mathrm{~km}$ di selatan Kota Tasikmalaya, Cikuya dan Lebaksiuh yang terletak kurang lebih $70 \mathrm{~km}$ arah selatan Kota Tasikmalaya.

Implementasi Wehrkreise dalam peristiwa ini di antaranya kerjasama antara tentara dan masyarakat, sehingga hubungan dengan pamong praja dan pegawai negeri lainnya dapat terpelihara dengan baik. Bahkan pada waktu-waktu tertentu dapat diadakan pertemuan antara para residen, bupati dan anggota-anggota dari jawatan sipil lainnya, serta dengan anggota-anggota badan perjuangan.

Taktik Wehrkreise dengan sendirinya telah mendidik dan membangkitkan semangat juang rakyat dan disiplin dalam menjalankan tugas. Penerapan taktik itu membuat para pemuda yang bertugas sebagai penghubung atau kurir yang dikenal sebagai "pasuratan" memiliki keberanian menerobos daerah musuh untuk menghubungi para pemimpin gerilya yang ada di kota, sekaligus menjadi penghubungan antara gubernur dengan para bupati dan residen, serta jawatan-jawatan yang saat itu menyebar di berbagai daerah.

\section{Tasikmalaya sebagai Ibukota Transisi}

Pusat kegiatan pemerintahan sipil Jawa Barat pada awalnya berada di Kota Tasikmalaya, tepatnya di Jalan Sutisna Senjaya Nomor 9. Namun, dikarenakan kedudukan pimpinan pemerintahan selalu menjadi sasaran serangan militer Belanda, maka lama tidaknya kedudukan pemimpin pemerintah di daerah tersebut sangat bergantung dari kondisi keamanan. Kenyataan inilah yang dialami Sewaka yang diangkat sebagai Gubernur Jawa Barat keempat pada tanggal 1 April 1947. Walaupun daerah Tasikmalaya masih dikuasai oleh pasukan republik, tapi tidak berarti keadaan di daerah ini dapat dikatakan aman dari serangan militer Belanda. Ancaman serangan militer Belanda selalu membayangi, sehingga setiap orang harus selalu waspada dan siap siaga (Hardjasaputra, 2006).

Pada waktu itu, keadaan Jawa Barat jauh dari ketentraman. Belanda terus berusaha memperluas kedudukannya dengan mendesak kedudukan pasukan republik. Hampir setiap hari banyak tempat di Jawa Barat yang jatuh ke tangan Belanda. Dalam keadaan ini, hubungan satu daerah dengan daerah lain sangat sukar dan seringkali terputus. Tidak sedikit daerah menjadi terisolir dari pusat pemerintahan sipil dan militer yang saat itu berkedudukan di Tasikmalaya.

Tasikmalaya merupakan salah satu daerah yang begitu diincar oleh tentara Belanda saat melancarkan serangan militer ke Jawa Barat, karena Kota Tasikmalaya saat itu memengang peranan sebagai pusat pemerintahan. Tasikmalaya dipilih menjadi ibukota Propinsi Jawa Barat karena di daerah ini terdapat beberapa objek vital, seperti: (1) adanya pusat komando Divisi Siliwangi, (2) adanya kedudukan staf pemerintahan Provinsi Jawa Barat, (3) adanya pusat Komando Pertahanan Daerah (Wehrkreise III), (4) adanya kantor pemberitaan Antara dan Merdeka, (5) adanya Radio Republik Indonesia (RRI) Bandung dan RRI Priangan Timur, (6) lapangan terbang Cibeurem yang disinyalir pihak Belanda sebagai pusat konsolidasi laskar bersenjata.

Karena besarnya potensi wilayah Tasikmalaya saat itu, maka tidaklah mengherankan jika tentara Belanda merasa perlu untuk melancarkan serangan militer. Serangan tentara Belanda itu dikenal dengan nama "agresi militer ke Kota Tasikmalaya”. Serangan tersebut merupakan batu loncatan dan upaya untuk menguasai seluruh wilayah Jawa Barat. 
Sebelum menyerang Kota Tasikmalaya, tentara Belanda terlebih dahulu menyerang Kota Kuningan dan Cirebon. Tentara Belanda berhasil menduduki kedua daerah itu pada tanggal 3 Agustus 1947. Keesokan harinya, Belanda melakukan serangan terhadap pertahanan pasukan Siliwangi di Cikijing, daerah perbatasan antara Cirebon dan Priangan. Sementara itu, Kompi Pelopor Belanda terus berjalan ke Distrik Kawali yang berhasil mereka duduki pada tanggal 6 Agustus 1947, kemudian mereka bergerak menuju Kota Ciamis dan berhasil mendudukinya. Dari daerah itulah tentara Belanda melakukan persiapan untuk melancarkan serangan ke Kota Tasikmalaya (Disjarah, 1994).

Sementara itu, situasi di Kota Tasikmalaya menjadi kacau akibat adanya kesalahan interpretasi terhadap berita kawat yang di kirim dari Cirebon. Berita kawat itu telah menimbulkan kegelisahan dan kepanikan di kalangan pasukan Siliwangi yang berkedudukan di Tasikmalaya, karena berkenaan dengan datangnya tentara Belanda yang bergerak dari Cirebon ke Kota Kuningan. Berita yang menyebar sampai ke Kota Tasikmalaya menyebutkan bahwa "tank musuh sudah berada di Kawali". Padahal berita kawat sebenarnya adalah "Belanda yang bergerak di Kuningan itu di kawali tank". Akibat dari kesalahan menanggapi berita tersebut, maka Komando Keamanan Daerah (KKD) Tasikmalaya, Mayor Suhari, segera memerintahkan persiapan untuk membuat berbagai rintangan di jalan dan melakukan penghadangan (Disjarah, 1994).

Sebenarnya, serangan militer Belanda ke Kota Tasikmalaya baru dimulai pada tanggal 21 Juli 1947 (Agresi Militer Belanda I) dengan melakukan serangan udara. Pada hari pertama, sekitar pukul 06.00 WIB, sebuah kapal terbang Bomber Mitchell Belanda terus menggempur Kota Tasikmalaya dengan sasaran lapangan udara Cibeureum, pabrik senjata, RRI Bandung (yang sementara pindah ke Kota Tasikmalaya), percetakan dan kantor harian Merdeka, stasiun kereta api, serta markas Divisi Siliwangi di Jalan
Oto Iskandardinata (sekarang di samping Bank Mandiri) (Disjarah, 1994).

Antara pukul 14.15-14.30 WIB, sebuah pesawat pemburu milik militer Belanda kembali menembaki lapangan udara Cibeureum dan jalan menuju Manonjaya. Sasaran lain dari serangan udara itu adalah kawasan Jalan Manonjaya (sekarang jalan Sutisna Senjaya), tempat kediaman Panglima Divisi Siliwangi. Di tempat ini pesawat tempur Belanda menjatuhkan bom roket secara membabi buta yang mengakibatkan banyak rumah penduduk rusak parah. Namun, sebuah bom yang dijatuhkan di halaman belakang kediaman Panglima Divisi Siliwangi tidak meledak (Disjarah, 1994).

Setelah terjadi serangan udara itu, Panglima Divisi Siliwangi, Kolonel A. H. Nasution, merasa bahwa markas Divisi Siliwangi yang berada di Jalan Manonjaya sudah tidak aman lagi. Oleh karena itu, Panglima Divisi Siliwangi segera melakukan beberapa tindakan:

1. Memindahkan markas Divisi Siliwangi ke Padayungan;

2. Memerintahkan Kapten Jamhuri selaku wakil Komandan Keamanan Kota (KKK) Tasikmalaya untuk segera mengadakan pertahanan kota dan melaksanakan pembumihangusan terhadap sarana-sarana vital;

3. Memerintahkan Kapten Udara R. Basir Surya selaku Komandan Panglima Udara Cibeureum untuk segera melaksanakan pembakaran atau bumihangus terhadap pangkalan udara dan sekaligus pesawatpesawat yang masih ada;

4. Penarikan pasukan-pasukan lokal yang ditempatkan di font-font lain untuk segera ke Tasikmalaya, di antaranya Batalyon II Sudarman dari front Jakarta Timur, Resimen X Pelopor dari Karawang, Kompi Komir Kartaman dari front Majalaya dan Detasemen II Garuda dari daerah Garut selatan. Sementara itu, pasukan Resimen VI di bawah pimpinan Letnan Kolonel Sadikin dikembalikan ke Karawang. Namun, 
perjalan pasukan Resimen VI terhambat oleh gerakan militer Belanda dan akhirnya terhenti di daerah perbatasan SubangSumedang (daerah Situraja, Darmaraja dan Wado) untuk kemudian melanjutkan gerilya.

Dua hari kemudian, Kota Tasikmalaya kembali mendapat serangan udara dari dua pesawat tempur Belanda. Serangan udara itu ditujukan ke kawasan stasiun kereta api, dan sebuah bom dijatuhkan di Jalan Galunggung yang mengakibatkan rumah penduduk di sekitar tempat itu hancur (Disjarah, 1994).

Melihat situasi yang begitu membahayakan, maka sebelum tentara Belanda dapat menguasai Kota, Kapten Jamhuri selaku Wakil Komandan KKK memerintahkan agar Kota Tasikmalaya segera dikosongkan. Kemudian orang-orang Tionghoa harus dikonsentrasikan dan diadakan gerakan bumihangus. Pengosongan kota dilaksanakan supaya tidak terjadi malapetaka yang akan menimbulkan korban, terutama rakyat. Mengingat Kota Tasikmalaya merupakan pusat pemerintahan sipil dan markas Divisi Siliwangi, maka serangan militer Belanda terhadap kota ini dilaksanakan secara besarbesaran. Oleh karena itu, penduduk terpaksa diungsikan ke luar kota, yaitu ke daerah-daerah pedalaman yang tidak terjangkau oleh operasi militer Belanda.

Pengkonsentrasian orang-orang Tionghoa dilaksanakan untuk menghindari terulangnya kejadian seperti di Cirebon. Ketika kota itu diduduki oleh Belanda, orang Cina segera menyusun pasukan untuk membantu Belanda dalam menghadapi pejuang-pejuang Indonesia. Dalam usaha pengkonsentrasian orang-orang Tionghoa di Tasikmalaya, maka terbentuklah "Tan Tia Tung" yang bermarkas di Jalan K.H Zaenal Mustofa.

Hardjasaputra (2006: 3) menjelaskan bahwa akibat tentara Belanda melancarkan Aksi Militer I ke Priangan Timur, termasuk Tasikmalaya, Gubernur Sewaka terpaksa menjalankan pemerintahan dengan berpindah-pindah tempat.
Gubernur mengubah taktik dengan membentuk "ambulans kantor", yaitu tiga orang stafnya selalu bergerak mengikuti gubernur. Dari Kota Tasikmalaya, gubernur pindah ke Indihiang, kemudian ke Cikoneng. Ternyata kedua tempat itu juga tidak luput dari serangan Belanda. Sebelum meninggalkan Indihiang, gubernur sempat menyampaikan instruksi kepada para residen dan bupati untuk menyusun siasat perjuangan dan berupaya menghindarkan diri dari tangkapan Belanda. Untuk menghadapi serangan Belanda, Gubernur Sewaka melakukan perundingan dengan Panglima Divisi Siliwangi di Taraju mengenai pelaksanaan perang gerilya di daerah Jawa Barat.

Karena semakin gencarnya serangan militer Belanda, terutama ditunjukkan pada objekobjek vital, maka pasukan Siliwangi berusaha sekuat tenaga untuk dapat mempertahankannya. Sementara itu, pemerintahan sipil yang dipimpin Gubernur Sewaka tidak mau meninggalkan Jawa Barat dan tetap mempertahankan Tasikmalaya sebagai basis perjuangan, walaupun pada akhirnya harus berpindah ke daerah pedalaman. Sebelum mengungsi, Sewaka sempat menyampaikan pidato yang ditujukan kepada rakyat Jawa Barat. Isi pidatonya menguraikan perihal serangan Belanda dan anjuran agar rakyat memiliki keberanian untuk menghadapi kesukaran dalam mempertahankan kemerdekaan dan kedaulatan negara (Hardjasaputra, 2006).

Selanjutnya, gubernur dan stafnya berpindah ke arah selatan Tasikmalaya, tepatnya di daerah Kecamatan Sukaraja. Di tempat ini gubernur dan stafnya sempat melaksanakan kegiatan pemerintahan. Namun, kedudukan gubernur di Sukaraja ternyata diketahui pihak Belanda. Tidak berlangsung lama, daerah sekitar pengungsian gubernur ditembaki dan dibom oleh pesawat tempur Belanda. Berdasarkan hasil musyawarah dan atas usul Kolonel Hidayat, tercapailah keputusan bahwa daerah Sukaraja harus segera ditinggalkan. Kemudian gubernur dan stafnya berpindah ke Karangnunggal. 


\section{Lebaksiuh menjadi Pusat Pemerintahan}

Ketika gubernur berada di pengungsian, komunikasi antarpejabat pemerintah di Jawa Barat dilakukan melalui surat-menyurat. Di setiap surat hanya tercantum nomor, tidak menggunakan alamat. Surat kepada gubernur sebagai contoh, ditulis "Kepada No. I di tempat". Begitu pula surat untuk residen, ditulis "Kepada No. II di tempat". Penomoran surat disusun berdasarkan tingkat jabatan di pemerintahan. Cara ini dipakai agar alamat para pejabat pemerintah di Jawa Barat tidak diketahui jika kurir pengirim surat tertangkap oleh Belanda. Setiap kurir sudah diajari alasan yang akan disampaikan kalau mereka tertangkap dan diintrograsi oleh tentara Belanda. Alasan yang disampaikan seragam; "surat ditemukan di jalan, tidak tahu apa isinya dan akan diserahkan ke pos penjagaan Belanda kalau surat itu kepunyaan Belanda.” Kurir surat menjadi juru penghubung komunikasi antara para pejabat pemerintah di Jawa Barat. Saat itu, komunikasi antara pemerintah daerah dengan pemerintah pusat yang berkedudukan di Yogyakarta mengalami kendala karena diblokade oleh Belanda. Oleh karenanya, pengambilan keputusan dalam pemerintahan di Jawa Barat diambil-alih oleh Gubernur Sewaka dan Letnan Kolonel Sutoyo selaku komandan Wehrkreise III (Hardjasaputra, 2006).

Hubungan di antara para pamong praja di Jawa Barat dapat terjalin berkat bantuan Tentara Nasional Indonesia dan masyarakat. Bahkan gubernur dapat melakukan rapat kordinasi dengan para redisen, bupati, anggota-anggota jawatan sipil dan badan-badan perjuangan. Namun, rapat kordinasi itu tidak dilaksanakan di Lebaksiuh. Sebagai pusat pemerintahan, Lebaksiuh dijaga dengan ketat. Setiap jalan menuju ke Lebahsiuh selalu dibuat kamuflase, misalnya beberapa puluh meter dari Lebaksiuh disamarkan sebagai sebuah kebun yang ditanami pisang, singkong dan ubi jalar. Bahkan jembatan Cijalu yang menuju ke Lebaksiuh dirobohkan oleh Kopral Udis atas perintah komandannya agar tidak ada yang bisa masuk ke Kampung Lebaksiuh (Disjarah, 1994).

Jadi, pelaksanaan rapat kordinasi para pejabat pemerintahan dilakukan di luar Lebaksiuh, yaitu di Kampung Pojok yang terletak di Desa Bongas (sekarang Desa Cintabodas). Setiap pertemuan dilakukan tertutup dan rahasia. Hanya orang-orang tertentu yang mengetahuinya. Dalam setiap rapat, gubernur selalu mendapat laporan tertulis maupun laporan lisan. Dengan demikian, gubernur selalu dapat mengetahui keadaan di seluruh wilayah Jawa Barat.

Sewaktu gubernur melakukan perjalanan ke daerah untuk mengunjungi para pegawai republik dan melihat dari dekat perkembangan situasi di daerah, gubernur selalu mendapati banyak rakyat yang mengalami berbagai kesulitan. Namun penderitaan itu tidak mempengaruhi semangan perjuangan. Rakyat tampak ikhlas dan memiliki kesadaran untuk bersatu padu membantu pemerintah dalam upaya menyelamatkan pemerintahan Republik Indonesia dari rongrongan Belanda, khususnya pemerintah Propinsi Jawa Barat (Hardjasaputra, 2006).

Satu hal yang menarik dan berkesan dalam perjuangan saat itu adalah bergabungnya tiga reporter dari Kantor Berita Antara menjadi staf gubernur. Ketiga reporter itu adalah A.Z. Palindih, Moch. Royani dan Moch. Saman yang ikut mengungsi ke Lebaksius. Mereka dengan inisiatif sendiri berusaha untuk membangun hubungan dengan Yogyakarta yang saat itu sedang terputus. Mereka berhasil membuat pemancar radio di Lebaksius. Hubungan pertama dengan pemerintah pusat Republik Indonesia di Yogyakarta dapat berjalan baik. Dengan demikian, Yogyakarta dapat mengetahui bahwa pemerintahan Indonesia di Jawa Barat masih berjalan. Padahal sebelumnya pemerintah pusat di Yogyakatya memperkirakan bahwa pemerintah Provinsi Jawa Barat sudah berakhir karena serangan Belanda.

Keberadaan pemancar radio tidak hanya menimbulkan kegembiraan di kalangan staf gubernur, tetapi juga seluruh penduduk Lebaksiuh 
karena setiap sore mereka dapat mendengarkan siaran radio. Bahkan penduduk dapat menikmati aliran listrik bertenaga diesel, sehingga rumah mereka terang benderang saat malam hari.

Setelah pemerintah pusat di Yogyakarta menerima informasi melalui pemancar radio tentang masih eksisnya pemerintahan republik di Jawa Barat, pemerintah pusat sering mengutus kurir ke Lebaksiuh. Kurir yang diutus ke Lebaksiuh adalah pemuda pelajar atau seorang tentara untuk menerima laporan gubernur yang akan disampaikan kepada pemerintah pusat di Yogyakarta.

Ada peristiwa yang menarik tentang kurir yang diutus pemerintah pusat ke Lebaksiuh. Peristiwa terjadi saat seorang tukang jamu yang tidak dikenali masuk ke kediaman gubernur. Kejadian ini tentu saja membuat gempar pejabat pemerintah dan penduduk Lebaksiuh. Setelah tukang jamu itu diperiksa dan diintrogasi, rupanya ia merupakan seorang tentara yang ditugaskan menjadi kurir oleh pemerintah pusat di Yogyakarta. Ia dikirim oleh pemerintah pusat untuk memastikan kebenaran berita tentang kedudukan pemerintah Propinsi Jawa Barat di Lebaksiuh (Hardjasaputra, 2006).

\section{Dukungan Masyarakat}

Penduduk Lebaksiuh bahu membahu membantu para pejabat pemerintah tanpa pamrih. Mereka rela berkorban demi membela kemerdekaan dan senantiasa taat kepada perintah pemuka masyarakat yang dipimpin oleh kepala desa dan tokoh agama. Sebaliknya, penduduk Lebaksiuh sangat membenci penindasan dan keangkaramurkaan. Hal ini dapat dibuktikan manakala mereka harus berhadapan dengan militer Belanda yang berusaha menduduki daerah Lebaksiuh. Berkat kegigihan dan ketangguhan penduduk, daerah Lebaksiuh pada masa revolusi relatif terhindar dari pendudukan militer Belanda. Bahkan berkat begitu kondusifnya Lebaksiuh, daerah tersebut dijadikan sebagai pusat pemerintahan Provinsi Jawa Barat selama kurang lebih tujuh bulan, sejak Agustus 1947 sampai Februari 1948.
Tidaklah berlebihan jika dikatakan bahwa berlangsung dan bertahannya pemerintahan "DASUNAS" Provinsi Jawa Barat selama tujuh bulan di Lebaksiuh, umumnya karena mendapat dukungan penduduk Kampung Lebaksiuh. Di samping itu, tidak bisa diabaikan pesan seorang dermawan H. Abdul Hamid, ayahanda dari H. Mohammad Muslih, yang dengan sukarela menyediakan rumahnya untuk tempat tinggal keluarga Gubernur Sewaka. Abdul Hamid secara sukarela menyumbangkan bahan makanan untuk rombongan pengungsi. Sebagai ucapan terimakasih yang sangat mendalam, Gubernur Sewaka dalam satu kesempatan pernah berkata kepada Abdul Hamid sebagai berikut: "untung didieu aya anjeun (Abdul Hamid), jaga tempat ieu bakal jadi tempat anu aya hargana" (Hardjasaputra, 2006).

\section{SIMPULAN}

Pembentukan Wehrkreise III pada tahun 1947 merupakan taktik untuk menghadapi tentara Belanda yang gencar melakukan serangan militer ke Jawa Barat. Wehrkreise III merupakan kantong-kantong pertahanan yang beranggotakan badan-badan perjuangan di Jawa Barat. Kantong-kantong pertahanan itu berada dalam satu komando, tapi setiap kantong pertahanan dapat melakukan perlawanan gerilya secara mandiri terhadap militer Belanda. Komandan Wehrkreise III tidak hanya membawahi badanbadan perjuangan, tetapi juga membawahi pemerintahan sipil di Jawa Barat.

Pada awalnya, pusat komando Wehrkreise III yang dipimpin Letnan Kolonel Sutoko dan pemerintah Propinsi Jawa Barat yang dipimpin Gubernur Sewaka berkedudukan di Kota Tasikmalaya. Sutopo dan Sewaka berkedudukan di satu daerah yang sama agar keduanya dapat berbagi informasi tentang pergerakan militer Belanda dapat tersampaikan kepada keduanya. Tasikmalaya dipilih sebagai ibukota Propinsi Jawa Barat dan pusat komando Wehrkreise III karena di daerah ini terdapat objek-objek vital, seperti kantor pemerintahan, markas pasukan 
Siliwangi, lapangan terbang, kantor media cetak dan radio. Namun, agresi militer Belanda pertama tahun 1947 telah meluluhkan Kota Tasikmalaya. Akibatnya, Sewaka dan Sutopo memutuskan untuk memindahkan tempat kedudukan mereka ke daerah yang lebih aman. Keputusan ini diambil agar pemerintahan republik di Jawa Barat dapat tetap berjalanan.

Gubernur Sewaka memilih Lebaksiuh sebagai ibukota yang baru. Daerah ini dinilai aman karena susah dijangkau oleh pasukan Belanda. Namun, blokade tentara Belanda membuat hubungan antara ibukota yang baru dengan daerah lain sulit dilakukan, terutama dengan Yogyakarta yang saat itu menjadi ibukota Republik Indonesia. Kesulitan ini akhirnya dapat diatasi melalui taktik Wehrkreise, di mana kerjasama tentara dan masyarakat dapat menjadi jembatan hubungan di antara para pejabat pemerintahan dan badan-badan perjuangan.

\section{REFERENSI}

Abdurahman, D. (1999). Metode Penelitian Sejarah. Jakarta: Logos Wacana Ilmu.

Disjarah. (1965). Peranan TNI AD dalam Perang Kemerdekaan. Bandung: Pussemad.

Disjarah. (1994). Siliwangi dari Masa ke Masa. Bandung: Disjarah.

Garraghan, G. J. (1957). A Guide to Historical Method. New York: Fordham University Press.

Gottschlak, L. (2008). Mengerti Sejarah. Jakarta: Yayasan Penerbit UI.

Hardjasaputra, A. S. (2006). Sewaka Tokoh Jawa Barat Yang Terlupakan. Tasikmalaya: Tanpa penerbit. 